BONPLANDIA 20(2). 2011

ISSN: 0524-0476

\title{
ETNOBOTÁNICA DEL “CORO”'(NICOTIANA PAA, SOLANACEAE): UN TABACO SILVESTRE POCO CONOCIDO DEL EXTREMO SUR DE SUDAMÉRICA
}

\author{
GUSTAVO F. SCARPA ${ }^{1} \&$ CINTIA N. ROSSO ${ }^{2}$
}

\begin{abstract}
Summary: Scarpa, G. F. \& C. N. Rosso. 2011. Ethnobotany of "coro" (Nicotiana paa, Solanaceae): A wild tobacco little-known of the Southern end of South America. Bonplandia 20(2): 391-404.

"Coro" is a wild tobacco of the Southern end of South America whose roots are used as a fumatory and masticatory from ancient times by indigenous groups. Notwithstanding there are some news about their employment since Colonial period, currently there is no consensus about its botanical identity. Its procedure of gathering, processing and consumption have also been sparsely described. Ethnobotanical fieldwork were carried out to the Southwest of the Chaco province, where plant specimens were collected with indigenous people. Available historical sources about "coro" was also analyzed. It was found in situ that Mocoví people currently smoke its roots mixed with tobacco in ceremonial contexts and extra-ceremonial. As a result of these analysis it was inferred that it was also used in the same way by Vilela, Qom (Tobas), Wichi, and Abipon indigenous people. The correspondence of the "coro" with Trichocline species is discarded because the absence of ethnobotanical records. It is confirmed that this fumatory corresponds to Nicotiana paa Mart. Crov., and new data about its gathering, processing and consumption is reported and discussed.
\end{abstract}

Key words: Fumatory, Nicotiana, Mocoví, Chaco.

Resumen: Scarpa, G. F. \& C. N. Rosso. 2011. Etnobotánica del "coro" (Nicotiana paa, Solanaceae): Un tabaco silvestre poco conocido del extremo sur de Sudamérica. Bonplandia 20(2): 391-404.

El "coro" es un tabaco silvestre de Argentina y Chile cuyas raíces son empleadas como fumatorio y mascatorio desde tiempos inmemoriales por grupos indígenas. Si bien existen noticias sobre su empleo desde la época colonial, en la actualidad no hay consenso sobre su identidad botánica a la par que sus modalidades de obtención, procesado y consumo han sido escasamente descriptas. Se efectuaron campañas etnobotánicas al sudoeste de la provincia del Chaco donde se colectaron ejemplares que responden a dicho nombre vernáculo en compañía de indígenas y se analizaron fuentes bibliográficas históricas disponibles. Se comprobó in situ que los mocovíes actualmente fuman sus raíces mezcladas con tabaco tanto en contextos ceremoniales como extra-ceremoniales. Como resultado del análisis bibliográfico se infiere que también lo emplearon en el pasado de manera homóloga indígenas vilelas, qom (tobas); wichi y abipones. Se descarta la correspondencia del "coro" con especies de Trichocline por la inexistencia de registros etnobotánicos al respecto. Se confirma que este fumatorio corresponde a Nicotiana paa Mart. Crov. y se presentan y discuten nuevos datos sobre su obtención, procesamiento y consumo.

Palabras clave: Fumatorio, Nicotiana, mocovíes, Chaco.

${ }^{1}$ Centro de Estudios Farmacológicos y Botánicos, Paraguay 2155 piso 17, C.A.B.A.

E-mail: gustavo22et@yahoo.com.ar

${ }^{2}$ Instituto de Altos Estudios Sociales (IDAES), Universidad Nacional de San Martín, Pcia. de Bs. As. 


\section{Introducción}

El uso de tabacos silvestres del género Nicotiana Adans. (Solanaceae) como fumatorio ha sido varias veces documentado a lo largo de toda América, como lo prueban las compilaciones realizadas por Wilbert (1987) para el subcontinente sudamericano y por Furst (1980) para América en general. Estos trabajos coinciden en señalar que las hojas de estas plantas -preferentemente- solían ser empleadas por grupos indígenas para una amplia variedad de propósitos de carácter sagrado-ritual así como en situaciones extra-ceremoniales. Entre los primeros merecen citarse la provocación de estados alternos de conciencia, su empleo como "alimento espiritual" de los dioses y como auxiliar de los chamanes en rituales de curación, los cuales hacían posible la obtención de distintos tipos de estados místicos e inclusive del trance extático característico de estos especialistas (Furst, 1980: 53 y ss). En todos los casos se le atribuye alguna propiedad de carácter psicoactivo, tales como efecto narcótico e incluso alucinógeno, dependiendo de la dosis administrada (Kvist \& Moraes, 2006; Furst, 1980).

En el extremo sur de Sudamérica particularmente, se citan numerosas especies de tabacos silvestres empleados como fumatorios (Kvist \& Moraes, 2006). Sin embargo, a diferencia de éstos y de otras plantas psicoactivas como el cebil (Anadenanthera colubrina (Vell.) Brenan var. cebil (Griseb.) Altschul) cuyos usos presentan una distribución relativamente amplia, la entidad "coro" solo fue referida para ciertas zonas del Chaco argentino y de los Andes meridionales de Argentina, Bolivia y Perú. La información existente sobre esta planta es escasa y en cierto sentido contradictoria, tanto desde la perspectiva botánica como antropológica y, si bien hay tempranas menciones a ella, su uso no ha merecido mayor atención por parte de los investigadores (Pérez Gollán \& Gordillo, 1993a: 301).

Desde comienzos del siglo XX hasta 1980, numerosos escritos de botánicos y médicos (Rojas Acosta, 1915; Di Lullo, 1929; Villafuerte, 1961; Schulz, 1963; Martínez Crovetto, 1978; 1980) coinciden en señalar que su identidad taxonómica corresponde a una especie del género Nicotiana (Solanaceae). Sin embargo, desde mediados de la década de 1970, Zardini (1977) refiere que la verdadera identidad del "coro" corresponde a varias especies del género Trichocline Cass. (Asteraceae). Esta situación contribuyó a que no se esclarezca con precisión su identidad botánica hasta la actualidad, hecho ya señalado en varios trabajos acerca de fumatorios narcóticos de Argentina donde se plantea esta disyuntiva en forma explícita (Capparelli et al., 2006; Pérez Gollán \& Gordillo, 1993a; 1993b; 1994).

Porotra parte, las informaciones etnográficas de carácter histórico que se disponen resultan en su mayor parte difusas e incompletas, indicando su empleo por grupos indígenas chaquenses y de los Andes meridionales de Argentina, Bolivia y Perú, sin precisar en muchos casos la adscripción étnica de quienes lo usaban ni mayores detalles acerca de su utilización. Entre los investigadores contemporáneos que se ocuparon del tema merece destacarse Martínez Crovetto quien, además de efectuar la descripción botánica precisa de la planta que aquí consideramos como "coro" (mediante la publicación de una nueva especie para la ciencia), brinda también algunas informaciones etnobotánicas acerca de su utilización. Otros autores también han registrado sus nombres vulgares entre etnias aborígenas de Argentina -especialmente del Chaco argentino-, así como sus usos medicinales y como fumatorio (Martínez Crovetto, 1980).

Por estas razones, el objetivo de este trabajo es presentar un panorama detallado de la etnobotánica del "coro" en función de datos inéditos tomados a campo y de fuentes bibliográficas disponibles, así como brindar elementos para el esclarecimiento de su identidad botánica.

\section{Materiales y Métodos}

Se efectuó una búsqueda exhaustiva de informaciones respecto al "coro" en fuentes bibliográficas provenientes de expedicionarios, etnógrafos, historiadores y botánicos, obtenidas de bibliotecas de la ciudad de Buenos Aires y Corrientes. 
Otra fuente de información provino de cuatro campañas realizadas al sudoeste de la provincia del Chaco entre los años 2008 y 2010 -concretamente a las localidades de Gancedo, Hermoso Campo, Charata, San Bernardo y Colonia General Necochea- de 15 días cada una. Durante las mismas se realizaron entrevistas etnobotánicas con integrantes de la etnia mocoví de la familia lingüística guaycurú, especialmente dirigidas a indagar sobre la significación cultural del "coro". También se coleccionaron, acondicionaron e identificaron especímenes vegetales silvestres y cultivados que respondieron al nombre de "coro" en compañía de representantes de dicha etnia, cuyas etiquetas se indican más abajo (así como también la de otro ejemplar estudiado de $N$. paa y de otras especies de Nicotiana mencionadas a lo largo del texto).

Este trabajo es parte de un proyecto más amplio destinado a estudiar la etnobotánica de los indígenas mocovíes que financia el Consejo Nacional de Investigaciones Científicas y Tecnológicas de Argentina.

Material estudiado: Nicotiana alata Link et Otto: ARGENTINA, Salta, Dep. Rivadavia, Misión La Merced Vieja, 26-XII2002, Scarpa, G. 507 (SI).

Nicotiana longiflora Cav.: ARGENTINA, Formosa, Dep. Bermejo, Vaca Perdida, 5-XII1996, Scarpa, G. 166 (BA).

Nicotiana paa Mart. Crov.: ARGENTINA, Chaco, Dep. Chacabuco, Colonia Necochea, XI-2008, Rosso, C. s.n., (BA); Dep. Gral. Pinedo, $4 \mathrm{~km}$ al NE de Gancedo por ruta nacional 89, 14-XII-2010, Scarpa, G. 798 (BA); Formosa, Dep. Matacos, Ing. G.N. Juárez, 21-II-1983, Arenas, P. 2236 (CTES).

\section{Antecedentes históricos del "coro"}

Una importante compilación de las fuentes históricas que mencionan el uso del "coro" para nuestro país ha sido realizada por Martínez Crovetto (1980) y por Pérez Gollán \& Gordillo (1993a).

Las primeras referencias del "coro" para nuestro país datan de fuentes del siglo XVIII, entre las que se cuentan las de Montenegro ([1710] 2007: 266); Lozano ([1754-1755] 1875: 425); Sánchez Labrador (citado por Ruiz
Moreno 1948: 229), Rubín de Celis (citado por Álvarez 1926); Dobrizhoffer ([1784] 1967: 526-27) y Jolís ([1789] 1972). Éstas citan el uso de sus raíces como fumatorio y mascatorio (algunos también como medicinal) para etnias pertenecientes a las familias lingüísticas tupi-guaraní (NEA), guaycurú (abipones, toba, provincias de Santa Fe y Chaco) y diaguita-calchaquí. Un lugar especial merece la cita de Faberman (2005: 188) respecto a la participación del "coro" en textos que documentan procesos judiciales contra hechos de "magia, hechicería y curanderismo" en el Tucumán Colonial de 1715.

Durante el siglo XIX, Carranza ([1884] 1972: 147) y Ambrosetti (1894: 153) registran el uso del "coro" para tobas y vilelas -chunupíes- respectivamente. Para inicios del siglo XX, citan su uso Rodríguez $(1927: 51,60)$ para guaycurúes (tobas y mocovíes) y Métraux (1996: 217) para tobas y vilelas. Alanís (1947: 75) refiere su uso para los descendientes de diaguitas en los Valles Calchaquíes (provincias de Catamarca, Tucumán y Salta), indicando además los nombres vernáculos en cada una de las lenguas indígenas. Estas citas nombran el uso del coro e indican que su raíz se fuma o bien se masca como sucedáneo del tabaco, mientras que en la descripción de sus efectos suele mencionarse sus efectos estimulantes, narcóticos y/o embriagantes.

Para los Andes centrales Cobo ([1653] 1964) señala que: "A la raíz del tabaco silvestre llaman los indios del Perú, coro, de la cual usan para muchas enfermedades...", mientras que Uhle -citado por Pérez Gollán \& Gordillo (1993a)- sobre la base de fuentes coloniales indica que "en la provincia de $\mathrm{La}$ Paz (Bolivia) se consumía el polvo de coro, además de tabaco".

\section{Identidad botánica del "coro"}

A pesar de que las fuentes antes mencionadas no refieren la identidad botánica de la planta en cuestión, varias de ellas coinciden en señalar su semejanza con el tabaco ( $N$. tabacum L.) en los términos siguientes: "[el coro]...aprecian mas que el tabaco los indios del Chaco y el humo tiene el olor de éste" (Sánchez Labrador citado por Ruiz Moreno, 1948); o también: 
"Por la forma de sus hojas, acritud y la fuerza productora de saliva [el coro] se le parece mucho [al tabaco]" (Dobrizhoffer, [1784] 1967: 527).

Entre las citas que sí involucran algún tipo de identificación botánica figuran, por un lado, los escritos de Zardini $(1975 ; 1977)$ y von Reis Altschul (1975), quienes identifican al "coro" con especies del género Trichocline -T. reptans (Wedd.) Hieron. principalmente- y, por el otro, los de Martínez Crovetto (1980) y demás autores citados en la introducción quienes sostienen que se trata de una especie de Nicotiana. A primera vista resulta paradójico que plantas con caracteres macroscópicos tan disímiles entre sí -como muestra la Tabla 1puedan ser confundidas, teniendo en cuenta que sus semejanzas se limitarían principalmente a que ambas especies son hierbas con raíces engrosadas que superponen su distribución espacial en Argentina.

Respecto a los datos etnobotánicos en los que se sustenta Zardini (1977) en su corta nota titulada "The identification of an Argentinian narcotic" para referir la identidad del "coro", se limita a señalar que: "My recent studies have disclosed that several species of the genus Trichocline bear the same common name in Argentina -coro- as well as the ethnopharmacologically significant name contrayerba". Además de afirmar que tal correspondencia se basa en haber registrado el mismo nombre vernáculo para especies de Trichochline, no detalla si sus "recientes estudios" corresponden a consultas de fuentes bibliográficas o si efectuó algún tipo de trabajo de campo. Tampoco cita ningún detalle acerca del lugar, época ni grupo humano de donde se obtuvieron estas informaciones, todo lo cual torna a sus datos altamente imprecisos desde el punto de vista etnobotánico. En realidad, las únicas fuentes de información etnográfica sobre el uso del "coro" en que se basa Zardini (1977) se limitan a Lozano ([1754-1755] 1875), Ambrosetti (1899) y a Martínez Crovetto (1968). Sin embargo, este último autor señala en trabajos posteriores que la identidad botánica del "coro" a la que alude es Nicotiana paa (Martínez Crovetto, 1980), por lo cual la confusión de la autora con una especie de Tricochline se vuelve aún más evidente. La falta de documentación etnográfica se comprueba también cuando sostiene que: "The same common name ["coro"] was used among all these natives [Mocovíes, Tobas and Matacos]", ya que en realidad cada una de estas etnias posee su propio nombre vernáculo en sus respectivos idiomas como se verá más adelante.

La cita del "coro" de von Reis Altschul (1975) como Trichocline incana (Lam.) Cass. para la República Argentina, sería errónea ya que esta especie es inexistente en nuestro país según el Catálogo de la Flora del Cono Sur (Zuloaga et al., 2009); se trata en realidad de una especie endémica de la República Oriental del Uruguay (Zardini, 1975: 683).

A diferencia de las identificaciones anteriores, las referencias que identifican al "coro" con especies de Nicotiana se hallan profusamente difundidas y documentadas según se observa en la Tabla 2. Las especies así referidas son Nicotiana alata, N. acuminata var. acuminata, $N$. longiflora (y su sinónimo N. acutiflora A. St.-Hil.) y N. paa, aunque las más comunes son las dos últimas. Entre dichos trabajos se destacan los de Martínez Crovetto (1978; 1980) quien no solo identifica al "coro" como una nueva especie para la ciencia, sino que además describe el empleo fumatorio de sus partes subterráneas por parte de un grupo humano culturalmente caracterizado y geográficamente localizado. Los autores no sólo tuvimos la oportunidad de coleccionar a campo en dos ocasiones la planta denominada "l'páa" por los indígenas mocovíes y "coro" por los criollos del Chaco (ver "material estudiado"), sino también de documentar entre ellos su uso como fumatorio durante los años 2008, 2009 y 2010, los cuales resultaron coincidentes con los registrados para el mismo grupo humano por Martínez Crovetto. Estas observaciones no solo confirman los datos obtenidos por este autor hace unos 44 años sino que además dan cuenta de la vigencia hasta nuestros días del uso fumatorio del "coro".

\section{Aspectos botánicos y autoecología del "coro"}

Nicotiana paa Mart. Crov. es una hierba 
G. F. Scarpa \& C. N. Rosso, Etnobotánica del “coro”: tabaco silvestre de Sudamérica

Tabla 1. Características macroscópicas de Nicotiana paa y Trichocline reptans.

\begin{tabular}{lll}
\hline \multicolumn{1}{c}{ Características generales } & \multicolumn{1}{c}{ Nicotiana paa } & \multicolumn{1}{c}{ Trichocline reptans } \\
\hline Hábito & Hierba perenne & Hierba perenne \\
Forma de vida & Sufruticosa & Planófita \\
Altura & $60-80 \mathrm{~cm}$ & $2-27 \mathrm{~cm}$ \\
Tallo & Erecto, poco ramoso & Planta acaule \\
Disposición de las hojas & Alternas & Arrosetadas \\
Forma de las hojas & Ovadas de borde liso & Oblanceoladas sinuadas o lobadas en el margen \\
Tamaño flores & $35-40 \mathrm{~mm}$ & $4-7$ mm \\
Disposición de las flores & En racimos plurifloros & En capítulos \\
Forma de las flores & Infundibuliforme & Tubulosas \\
Color de las flores & Blancas & Amarillas, rojas o anaranjadas \\
\hline
\end{tabular}

Tabla 2. Referencias al "coro" como especie del género Nicotiana

\begin{tabular}{|c|c|c|c|c|c|}
\hline Nombre científico & USO & Forma de uso & Órgano & Fuente & $\begin{array}{c}\text { Zona } \\
\text { geográfica }\end{array}$ \\
\hline Nicotiana alata & Fumatorio & $\begin{array}{l}\text { Raíz mascada o picada } \\
\text { para fumar en pipas. }\end{array}$ & Raíz & Schultz (1963: 63) & Chaco \\
\hline Nicotiana longiflora & Medicinal & & & $\begin{array}{l}\text { Rojas Acosta } \\
(1915: 112)\end{array}$ & Corrientes \\
\hline Nicotiana longiflora & Medicinal & $\begin{array}{l}\text { Como antiinflamatorio y } \\
\text { febrífugo }\end{array}$ & $\begin{array}{l}\text { Hojas } \\
\text { Raíz }\end{array}$ & Di Lullo (1929: 63-75) & $\begin{array}{l}\text { Santiago del } \\
\text { Estero }\end{array}$ \\
\hline Nicotiana longiflora & $\begin{array}{l}\text { Fumatorio } \\
\text { y medicinal }\end{array}$ & $\begin{array}{l}\text { Raíz o tallo picados } \\
\text { mezclado con tabaco }\end{array}$ & Raíz & $\begin{array}{l}\text { Villafuerte (1961: } \\
\text { 203-204) }\end{array}$ & Catamarca \\
\hline $\begin{array}{l}\text { Nicotiana acuminata } \\
\text { (Graham) Hook. var. } \\
\text { acuminata }\end{array}$ & $\begin{array}{l}\text { Medicinal y } \\
\text { veterinario }\end{array}$ & $\begin{array}{l}\text { Hojas soasadas con } \\
\text { aceite o en infusión }\end{array}$ & Hojas & Gaviorno (com. pers.) & San Juan \\
\hline Nicotiana paa* & Sin usos & & & $\begin{array}{l}\text { Millán (1928: 187) } \\
\text { Como "corayuyo", } \\
\text { "tabaco cimarrón"y } \\
\text { "lagaña de perro" }\end{array}$ & Cuyo y NOA \\
\hline Nicotiana paa & Fumatorio & Fumatorio & Rizomas & $\begin{array}{l}\text { Martínez Crovetto } \\
(1978: 10)\end{array}$ & Chaco \\
\hline Nicotiana paa & Fumatorio & Fumatorio & Rizomas & $\begin{array}{l}\text { Martínez Crovetto } \\
(1980: 456)\end{array}$ & Chaco \\
\hline Nicotiana paa & $\begin{array}{l}\text { Fumatorio y } \\
\text { medicinal }\end{array}$ & $\begin{array}{l}\text { Fumatorio } \\
\text { Baños }\end{array}$ & Raíz & Scarpa \& Rosso & Chaco \\
\hline
\end{tabular}

* Citada como Nicotiana cavanillesii Dunal var. albiflora (Comes) Millán.

casi totalmente glabra con raíces gemíferas engrosadas, hojas pecioladas, ovadas de borde liso. Sus flores son horizontales a erectas; cáliz con lacinias equilongas menores que el tubo; corola completamente blanca, limbo actinomorfo horizontal con lacinias profundamente emarginadas, o bilobadas; estambres y estilos incluidos (Cocucci
\& Hunziker, 2005). Pertenece a la sect. Noctiflorae Goodsp. (Knapp et al., 2004), de cuya especie tipo se diferencia principalmente por sus raíces gemíferas y lóbulos corolinos profundamente emarginados (ver Fig. 1 A-C).

La primera referencia botánico-taxonómica sobre esta planta fue publicada por Comes (1899) en base a material coleccionado por 


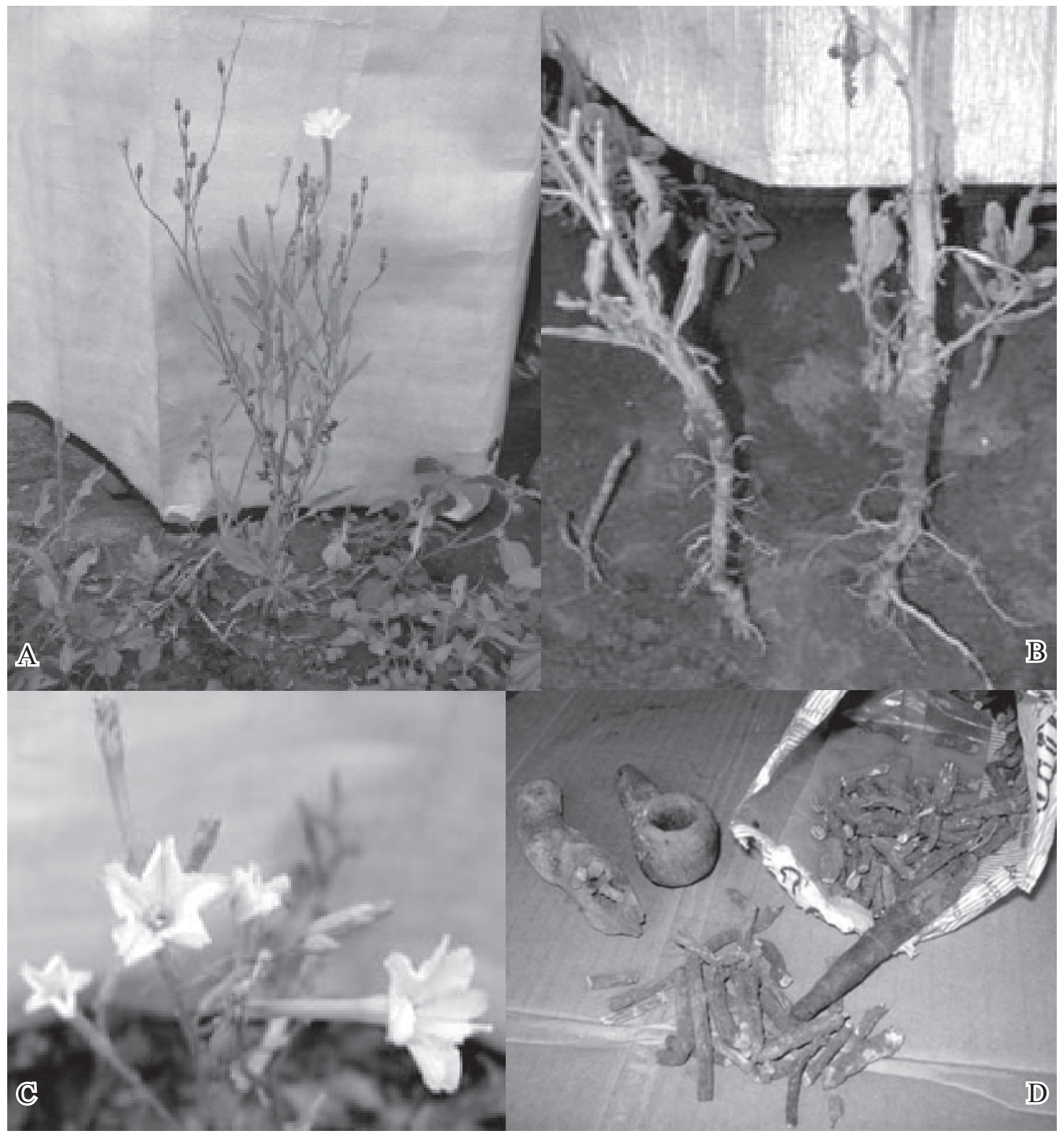

Fig. 1. Nicotiana paa. A: Planta. B. Aspecto de las raíces. C. Flores. D. Pipa utilizada y material procesado.

Spegazzini en la zona de prepuna aledaña a los valles Calchaquíes de la provincia de Salta (Goodspeed, 1954). Allí, Comes la considera como una variedad de $N$. noctiflora Hook., la cual denomina como “albiflora”. Millán (1928: 187) también considera a este taxón como una variedad en el tratamiento taxonómico realizado sobre el género Nicotiana aunque, en su caso, como perteneciente a $N$. cavanillesi (Nicotiana cavanillesii var. albiflora (Comes) Millán).
Contrariamente a los autores citados Martínez Crovetto (1978) considera que sus diferencias respecto a los demás taxones no se limitan al rango varietal de una especie conocida sino que se trata de una nueva. Su decisión de elegir como epíteto específico su nombre en lengua mocoví "paa" constituye un homenaje de Martínez Crovetto a este pueblo cuyos representantes chaqueños compartieron con él sus conocimientos sobre esta planta.

Acorde con el Catálogo de la Flora del 


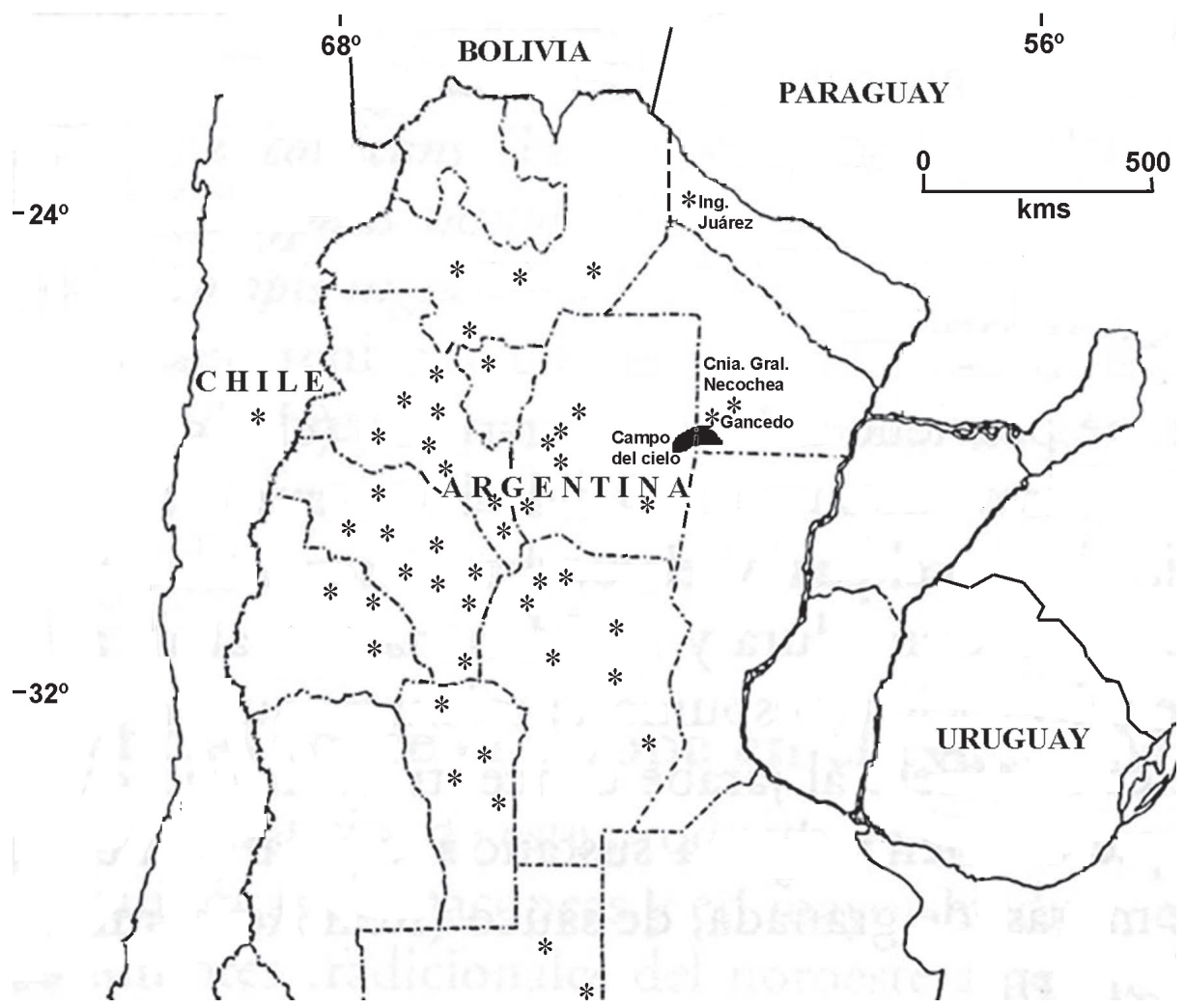

Fig. 2. Distribución geográfica de Nicotiana paa, área de estudio y localización del asentamiento mocoví.

Cono Sur (Zuloaga et al., 2009), N. paa es una planta endémica de la Argentina que crece en las provincias de Salta, Chaco, Tucumán, Catamarca, Santiago del Estero, La Rioja, San Juan, Córdoba y San Luis y también de la República de Chile (III Región). Según el análisis del ejemplar Arenas 2236 -ver "material estudiado"-, se amplía la distribución antedicha a la provincia de Formosa (ver Fig. 2).

Las informaciones sobre su autoecología son ciertamente escasas. Pudimos constatar a campo que se halla asociada a suelos francoarenosos, lo cual concuerda claramente con la distribución geográfica de esta especie en territorio argentino. En efecto, se la ha coleccionado frecuentemente creciendo en los valles andinos del NOA que presentan suelos jóvenes de granulometría gruesa, mientras que su presencia disminuye sensiblemente hacia las tierras bajas donde los suelos de este tipo son azonales (es decir, se hallan limitados a bordes de cursos de agua y a ciertas zonas muy acotadas que no responden a la matriz edáfica de la región). Esto último se correlaciona con la abundancia relativa de ejemplares de herbario coleccionados para una y otra región (ver Fig. 2).

Según relatos indígenas y nuestras propias observaciones personales, pudimos constatar que se trata de una planta higrófila. En efecto, durante la primavera de 2008 sólo registramos su presencia en huertos indígenas donde las plantas estaban sometidas a riego periódico, mientras que en los lugares donde suele crecer silvestre según nuestros colaboradores mocovíes (alrededores de la localidad de Gancedo, Chaco), no se pudo hallar ningún ejemplar. En estos mismos sitios, durante la misma época pero del año 2010, en cambio, sí se la pudo coleccionar creciendo vigorosamente en forma de parches a los costados de una isleta de bosque. Estas diferencias se habrían debido a que durante la primavera del 2008 las precipitaciones en dichos lugares fueron sustancialmente menores a las de otros años (fue un "año seco"), mientras que en 2010 las mismas ocurrieron normalmente, fenómeno 
que habría favorecido la emisión de brotes aéreos de sus raíces gemíferas.

Otro dato que pudimos registrar es su condición de planta heliófita y ruderal ya que fue hallada vegetando a cielo abierto sobre suelos modificados, mientras que en el sotobosque de la isleta boscosa aledaña no fue encontrado ningún ejemplar.

Según la "Germplasm Resources Information Network - (GRIN) [Online Database]" (USDA et al., 2011), N. paa es catalogada como especie de importancia económica como fuente de genes, debido a que es considerada como pariente genético terciario del tabaco basado en las afinidades que posee dentro del género Nicotiana.

\section{Aspectos etnobotánicos del "coro"}

A continuación se analiza la nomenclatura vernácula asignada al "coro", las diversas modalidades de su obtención, procesamiento, almacenamiento y consumo.

Según los principales estudios que compendian la etnobotánica de distintos grupos humanos del Chaco argentino (Arenas, 2003; Filipov, 1997; Scarpa, 2000; Suárez, 2011; Martínez Crovetto, 1964; 1965; 1968; Vuoto, 1981), se desprende que el único grupo humano que emplea $N$. paa como fumatorio en la actualidad son los indígenas mocovíes de la provincia del Chaco. Por esta razón y por haber registrado informaciones respecto a esta temática en trabajos de campo con esta última etnia, la mayoría de los datos etnobotánicos que a continuación se describen fueron referidos por representantes de este grupo étnico. Quienes suministraron las informaciones fueron personas mayores de 50 años, ya que los jóvenes no la utilizan ni conocen la planta.

Los mocovíes son un grupo indígena perteneciente a la familia lingüística Guaycurú (junto con los tobas, pilagás, caduveo y abipones) que tradicionalmente se dedicaban a la caza y la recolección. En la actualidad, debido a complejos procesos sociohistóricos, se dedican a otras actividades para su subsistencia tales como la agricultura, el trabajo asalariado $\mathrm{u}$ obtienen ingresos a partir de planes sociales. La mayoría de los miembros de esta etnia viven en asentamientos ubicados en el sudoeste de la provincia de Chaco y en el norte de Santa Fe.

a.) Nomenclatura vernácula: La voz "coro" es la denominación más difundida entre los criollos de Argentina para N. paa, la cual constituye una castellanización del vocablo "k'oro" o "k'uru" o "kkuri", de procedencia quechua-aymara tal como lo señalan las fuentes (Montenegro, 1710; Oblitas Poblete, 1969: 213; Soukup, 1970; Pérez Gollán \& Gordillo, 1993a: 304) (otras variantes fonético-fonológicas citadas son "kkoro", "kkora", "qoro", "qora", "kkuru” o "kkura"). Asimismo, en la zona andina y serrana de Argentina suele también denominarse "corayuyo" o "coro-yuyo" (provincias de Catamarca, La Rioja y San Juan); "crespinel" (Córdoba) y también "chosni yuyo" (Catamarca y Tucumán) (Cocucci \& Hunziker, 2005: 11), aunque menos frecuentemente. Los registros de nombres indígenas de esta planta corresponden a grupos étnicos de la región del Chaco argentino. El nombre mocoví referido por nuestros colaboradores fue "l'páa" (lit. "su raíz"), aunque en menor medida "naserek l'paá" (lit. "tabaco su raíz”). Según Carranza ([1884] 1972) los toba o qom (pertenecientes a la misma familia lingüística) le asignaban el mismo nombre. Por último, Dobrizhoffer ([1784] 1967) indica el fitónimo "noetá" para los indígenas abipones del sudeste del Chaco (que a diferencia de los anteriores no poseen representantes en la actualidad). En los últimos casos, no sabemos si se trata de lexemas primarios, secundarios o simplemente de nombres descriptivos.

b.) Obtención: Los datos bibliográficos coinciden en afirmar que los aborígenes del Chaco argentino emprendían viajes en determinadas épocas del año a los lugares donde crecía esta planta especialmente motivados para recolectarla (Álvarez, 1926; Santamaría, 2007) $)^{1}$. Concordante con esto último, nuestros colaboradores mocovíes señalaron que algunos

\footnotetext{
1 “...en cierta estación del año vienen a las márgenes del Río Bermejo, a cavar o sacar una raíz silvestre llamada koro: que sólo la mascan continuamente, siendo para ellos de primera necesidad, así para preservarse de los efectos de una atmósfera infestada, como de las mordeduras continuas de los reptiles ponzoñosos..." (Alvarez, 1926). “...es recogida anualmente después de una migración masiva donde no faltan encuentros interétnicos pacíficos” (Santamaría, 2007).
} 
se dirigen todavía hoy varias decenas de kilómetros hacia el sudoeste de sus actuales asentamientos en búsqueda de esta planta hacia fines de la primavera, luego de las primeras lluvias estacionales (inicios de diciembre). Los datos relativos a la disponibilidad espacial y temporal de las poblaciones de "coro" señalada por los indígenas fueron confirmados a campo por los autores. La recolección se efectúa removiendo las plantas enteras de raíz. Una vez en sus asentamientos extraen de cada una de ellas sus raíces y hojas, desechando el resto. En determinadas ocasiones, los mocovíes recolectan varias plantas enteras a fin de transplantarlas en sus huertas peridomésticas. Las noticias precisas que tenemos de su cultivo datan de 1964 por Martínez Crovetto (1978). Los autores tuvimos oportunidad de documentar su cultivo en el mismo sitio que lo hiciera este autor hace 44 años, ocasión en la que coleccionamos uno de los ejemplares antes citados (Rosso, s.n.). El cultivo consistía en unos pocos ejemplares que se hallaban creciendo junto con otros cultígenos -alimenticios y medicinales- en huertas de pequeñas dimensiones $(5 \times 2 \mathrm{~m})$ localizadas a cielo abierto a escasos metros de sus viviendas. Pudimos observar que a los dos años de colectado el ejemplar esta huerta fue abandonada, lo cual permitiría inferir que la práctica de su cultivo se hallaría amenazada.

c.) Procesamiento y almacenamiento: Una vez en sus viviendas las raíces del "coro" son almacenadas dentro de bolsas cerradas, sin mediar proceso alguno. Antaño se guardaba en una bolsa especialmente alargada y estrecha, confeccionada a tal fin con el cuero extraído del largo cuello de un "suri" adulto (Rhea americana L.). Para ello, al despellejarlo se tenía especial cuidado de extraer el cilindro entero, para luego coser sus extremos con una "vena" o tendón extraído de la pierna del mismo animal, el cual se empleaba como hilo. Actualmente se usan bolsas de arpillera o de género debidamente cerradas. Nuestros colaboradores sostienen que si no se toman estas precauciones el fumatorio "se echa a perder". Una vez que se desea fumar se rompe la bolsa, se extrae una raíz entera, se troza o muele y se mezcla con una igual cantidad de inflorescencias molidas de "cola de zorro" (Cortaderia selloana (Schult. \& Schult. f.) Asch. \& Graebn., Poaceae) o bien con tabaco
(N. tabacum) ya procesado. Estos agregados se utilizan como atemperantes del "coro", ya que fumarlo puro ocasionaría mareos y somnoliencia pronunciadas, según nuestros colaboradores. Una vez mezclado, se deja secar durante un día y medio aproximadamente antes de colocarlo en la pipa para fumarlo. Sus hojas, menos frecuentemente utilizadas, también deben ser previamente secadas, molidas y mezcladas con tabaco para poder emplearlas como fumatorio.

\section{d.) Características de su consumo.}

d.1.) Formas y finalidades: Actualmente los mocovíes introducen el material procesado en hornillos de pipas y lo fuman sin tragar el humo. Las pipas que tuvimos oportunidad de documentar son del tipo tubular de unos $15 \mathrm{~cm}$ de largo elaboradas a base de arcilla cocida de confección simple (ver Fig. 1D). Martínez Crovetto (1980), por su parte, cita el empleo de pipas confeccionadas con madera de Sideroxylon obtusifolium (Roem. \& Schult.) T.D. Penn. (Sapotaceae), las cuales hoy ya no son utilizadas. Las mujeres eran más propensas a mascar sus raíces molidas cuidando de no tragar la saliva, aunque también fumaban con fines medicinales. Otra manera de fumar el "coro" registrada a campo es incorporar el material procesado -antes descripto- en cigarros (de menos de $10 \mathrm{~cm}$ de longitud) confeccionados con chala de maíz o con hojas de tabaco. El objetivo de su consumo entre los mocovíes no difiere mayormente del de otras etnias de las tierras bajas sudamericanas. Además de su empleo a manera de estimulante-recreativo -como el tabaco común-, también resultó frecuentemente mencionada su función medicinal. Respecto al primer tipo de uso, refirieron que o bien puede emplearse de esa manera todos los días teniendo la precaución de mezclarlo con los atemperantes ya indicados o incluso puede llegar a fumarse puro sin ningún otro aditivo pero hasta en dos ocasiones al mes como máximo. Desde el punto de vista medicinal nos fue principalmente señalado su capacidad de otorgar fortaleza ("fuerza") a quien lo fuma. En efecto, nuestros colaboradores refirieron ambiguamente que se emplean para el tratamiento de un cuadro de “debilidad corporal”. No especificaron ningún nombre vernáculo para este trastorno, sino una perífrasis en lengua mocoví " ("lalolaGaik siyíne laGasiem") cuya traducción aproximada 
sería "cuando uno no puede levantarse". Se emplea también -como fumatorio- en casos de gripe y resfriados fuertes. En líneas generales, los mocovíes dieron cuenta que fumar "coro" constituye una verdadera panacea, bueno contra cualquier dolor corporal. La aplicación de baños a los recién nacidos con el macerado o decocción de sus hojas suele prescribirse con fines preventivos "para que no lo agarre en ninguna parte [la enfermedad]", en cambio, con fines terapéuticos propiamente dichos suelen emplearse contra la varicela y el sarampión (usos que serían préstamos de sus criollos vecinos quienes emplean el tabaco de la misma manera para idénticos fines). Su condición de otorgar "fortaleza" también nos fue referida para los chamanes mocovíes o "pioGonák", quienes lo fuman o mascan durante sus ritos terapéuticos. En efecto, ellos señalaron que mediante su consumo el chamán tiene "más poder" para curar ya que el humo del "coro" llegará hasta los espíritus auxiliares a quienes debe convocar para lograr la curación del enfermo. Es importante notar aquí que, además del "coro" y al igual que la mayoría de los indígenas del Gran Chaco y de otras etnias de Sudamérica -como los waraos (Wilbert, 1972)- , los mocovíes no usaban otros narcóticos más que el tabaco común $(N$. tabacum). Por último, los gases producto de la combustión de las raíces de $N$. paa también son empleados como repelente de víboras e insectos hasta la actualidad por los mocovíes, tal como citara Álvarez (1926) para comienzos del siglo XX.

d.2.) Ámbitos de consumo: Las informaciones sobre este aspecto fueron escasas; nuestros colaboradores se mostraron especialmente parcos frente a estas indagaciones. Según lo relatado por unos pocos colaboradores ancianos y lo registrado en la bibliografía -ver más abajopodemos identificar dos clases de ámbitos de consumo, uno colectivo y otro personalíntimo. El primero de ellos incluye tanto las reuniones de toda la comunidad en rituales y celebraciones (conocidas con el nombre de "juntas"), como situaciones de visitas de familiares o aliados distantes. A este último respecto, Furlong (1938: 85), citando fuentes jesuíticas del siglo XVIII, refiere que: "Cuando se convidan con mascada de tabaco, o con el coro, raíz que era antes su tabaco, lo hacen con toda esta asquerosa pulidez. Coge uno el tabaco, máscalo, $[\ldots]$ pone solamente sal en la mano, saca el tabaco mascado de la boca, pónelo sobre la sal amásalo con ella, y hace una bola. Luego con mucha pulidez hace tantas partes cuantos son los presentes, dáles con cortesía a cada uno su parte, y ellos con su "naatic" que es la expresión del agradecimiento, la reciben, sin asco la meten a sus bocas, y prosiguen mascando y saboreándose con ella". Según lo recabado en conversaciones informales, tenemos la impresión que su consumo personal en ocasiones extra-ceremoniales se realiza solitariamente en situaciones de intimidad. Por último debe destacarse que fumar "coro" no constituye actualmente entre los mocovíes del Chaco una adicción ni estaría asociada a sujetos que poseen costumbres adictivas (alcoholismo, tabaquismo). De hecho, personas ampliamente legitimadas por el grupo social (que ofician como sus representantes) que asisten a ritos religiosos cristianos donde dicha clase de conductas es expresamente interdicta, suelen consumir esporádicamente el "coro" sin mayores prejuicios.

d.3.) Aspectos perceptuales citados: Los datos bibliográficos coinciden en señalar que las características perceptuales y los efectos de fumar "coro" serían del todo semejantes a los del tabaco (Sánchez Labrador, citado por Ruiz Moreno, 1948; Dobrizhoffer, [1784] 1967; Rodríguez, 1927; Carranza, [1884] 1972), tanto por el aroma del humo producido como por su acción sobre el cuerpo humano. Pocos autores (Lozano, [1754-1755] 1875; Ambrosetti, 1894) mencionan, en cambio, su poder embriagante y hasta narcótico, aunque sin señalar las cantidades consumidas en estos casos. Acorde con estos datos, nuestros colaboradores mocovíes también sostuvieron respecto al "coro" que es parecido a fumar tabaco, aunque a diferencia de éste, señalaron que suele producir somnoliencia, mareos y en algunas ocasiones descomposturas.

\section{Discusión y Conclusiones}

Según el análisis efectuado sobre la identidad botánica del "coro" se infiere que la metodología empleada por Zardini 
(1977) para asociarla con una especie del género Trichocline se reduce a deducir su identidad botánica -y sus propiedades narcóticas- sobre la base de su nombre vulgar. De la misma manera, a partir de los demás nombres vernáculos asignados a $T$. reptans -"contrayerba", "árnica" y "topsaire plateado" (Zardini, 1975)-, la autora también podría haber asociado esta planta con su potencial utilización como veneno para flechas (como las "contrayerbas"); con los mismos usos medicinales que las especies del género Arnica L. (Asteraceae) del hemisferio norte o como los helechos de la Puna conocidos genéricamente como "topasaire". Sobradamente conocida es la inconveniencia de aplicar este método de identificación, dado que las relaciones entre los nombres vulgares y los científicos raramente suelen ser de tipo bi-unívoca.

La voz "coro", que tanto en lengua aymara como en quichua significa "hierba" (razón por la cual participa en nombres compuestos de otras especies), habría sido difundida por colonos españoles a través de todo el extremo meridional de Sudamérica para aludir a cualquier clase de tabaco silvestre o "cimarrón". En efecto, de esta misma manera se define "kkuri" en el diccionario de plantas medicinales de la farmacopea Callawaya (Oblitas Poblete, 1969: 213), dato que resulta coherente con los abundantes registros de la utilización del quichua por los españoles como lengua franca en todo el altiplano y zonas bajas adyacentes. Dado el carácter genérico de este fitónimo, el mismo se habría aplicado en distintas regiones a diferentes especies de plantas fumables, preferentemente del género Nicotiana. En el Altiplano de Bolivia y Perú, por ejemplo, estas especies habrían sido mayormente $N$. rustica L. y $N$. paniculata L. respectivamente (Oblitas Poblete, 1969: 337; Soukup, 1970). Por todo esto consideramos que el empleo de un fitónimo de amplísimo campo semántico como la voz "coro" habría operado como una forma velada y ambigua de aludir a muchas plantas fumables de esta parte del mundo, en virtud de su efecto estimulante o narcótico (de la misma manera que la "marihuana" Cannabis sativa $\mathrm{L}$. es designada vulgarmente como "la hierba" en el mundo de habla hispana). El mecanismo semántico que asocia esta planta con la imagen prototípica de un atributo morfológico, también es compartido entre los mocovíes quienes la designan como "su raíz".

Las causas por las cuales se habría identificado al "coro" como $N$. longiflora, $N$. alata o $N$. acuminata -según se muestra en la Tabla 1- obedecerían a varias razones, entre las que se destacan su condición de "tabacos silvestres" fumables, las similitudes macroscópicas de estas últimas con $N$. paa y/o a que fueron realizadas antes de que esta especie fuera descripta por primera vez para la ciencia (1978). Otras causas de tal confusión podrían haber sido las similitud de aromas de los gases producto de la combustión de sus hojas con las de N. paa -en virtud de la presencia de nicotina- y la superposición existente entre sus respectivas distribuciones geográficas. Sin embargo, resulta muy poco probable que tal confusión se mantuviera respecto al uso de sus raíces como fumatorios, ya que éstas son marcadamente diferentes a las de las otras especies. En efecto, los mocovíes destacaron las diferencias morfológicas y de color entre las raíces de $N$. longiflora y las de $N$. paa, en cuanto a que las primeras son napiformes y de color blanco definido, mientras que las de $N$. paa son lineares y de color castaño-rojjizo (ver Fig. 1B).

Se ha podido observar que en el sudoeste del Chaco, $N$. paa crece escasamente en toda la región lo cual, unido a la lejanía de los lugares de residencia actuales de los mocovíes, habría determinado el mantenimiento de su cultivo hasta nuestros días. A diferencia de otras especies ruderales que vegetan en esta zona -la cual ha sufrido profundas modificaciones debido al proceso de agriculturización operado-, N. paa parece no haber ampliado su distribución espacial. Esto sugeriría que las razones de su distribución acotada estarían vinculadas principalmente con otras variables ambientales tales como un especial tipo de suelos. Esto último es coherente con lo señalado por las fuentes históricas en cuanto a que "Campo del Cielo" constituía desde antaño la zona por excelencia donde los indígenas chaquenses acudían a recolectar este fumatorio.

Los tipos de usos registrados para N. paa 
no difieren de los citados para la mayoría de las especies de Nicotiana a lo largo de toda América, es decir, como fumatorio, mascatorio, medicinal y como insectífugo (Schery, 1952: 301). Incluso su uso medicinal coincide en cuanto a su condición de panacea con la representación médico-terapéutica de los tabacos silvestres en buena parte de Sudamérica (Furst, 1980).

En cuanto a su uso ritual también se registraron semejanzas respecto a otros tabacos, especialmente como agente auxiliar para que el chamán logre su intermediación con lo sobrenatural. Sin embargo, la descripción de su acción por parte de los indígenas mocovíes no se efectuó en términos de producir un efecto narcotizante capaz de alterar el estado de conciencia y así permitir el "vuelo" del alma/espíritu del chamán, sino más bien en el sentido de suministrar la fortaleza necesaria para alcanzar ese estado. Estas observaciones conjuntamente con nuestra experiencia, coinciden con la mayoría de las fuentes históricas en cuanto a que sus efectos no serían muy diferentes a los provocados por fumar tabaco, por lo cual su condición de "narcótico" sería tan aplicable al "coro" como a los demás "tabacos". Su consumo en ocasiones extraceremoniales realizado en un contexto de intimidad, sumado a la gravedad que tiñe las descripciones de su consumo asociado a su significación en contextos chamánicos para los mocovíes y en otras fuentes históricas en tiempos de la Colonia (Faberman, 2005), nos permite coincidir con la caracterización de "semi-sagrado" que poseería su consumo tal como fue descripto para otras especies de Nicotiana respecto de pueblos precolombinos norteamericanos por Schery (1952: 301).

El uso de raíces como sustancia fumable resulta muy poco frecuente en la bibliografía consultada, lo cual otorga aún mayor relevancia a los datos aquí presentados; en efecto, respecto a raíces fumables de especies de Nicotiana la única cita encontrada refiere al consumo de las raíces de $N$. rustica y $N$. tabacum por los iroqueses de América del Norte (Moerman, 1998: 356).

En base a los numerosos datos etnobotánicos científicamente documentados que indican además de una identificación botánica confiable el grupo humano que lo utiliza y al análisis comparativo realizado, podemos concluir que el "coro" citado para Argentina corresponde indudablemente a N. paa. Asimismo, las referencias que asocian al "coro" como una especie de Trichocline son claramente incorrectas, provienen de trabajos cuya finalidad y metodología responde a la taxonomía botánica, siendo los análisis de la fitonimia vulgar y de las prácticas culturales estrictamente subsidiarios al tema central de sus investigaciones. Esta situación ha determinado que la cita de datos etnobotánicos por parte de taxónomos en nuestro país haya tomado -a veces- la forma de dato anecdótico y/o exótico y como tal desprovisto de toda pretensión de precisión científica. Este escenario no hace más que realzar la necesidad de investigaciones etnobotánicas que por su especificidad relativa se abocan a describir y analizar en sus precisos contextos ecológicos y culturales las prácticas de grupos humanos determinados respecto al entorno vegetal que los rodea.

Se destaca que a pesar de los siglos de introducción del tabaco comercial entre indígenas chaquenses todavía se le otorgue un lugar preponderante entre sus fumatorios, hasta el punto de cultivarlo en la actualidad. Esta observación, sumada al papel de este artículo en ámbitos culturales vinculados a sus creencias más íntimas y a la emotividad expresada hasta nuestros días en la forma afectuosa de denominarlo -corito-, no dejan lugar a dudas de la elevada significación que le confieren los únicos indígenas que todavía fuman estas raíces.

\section{Agradecimientos}

A nuestros colaboradores mocovíes Marcos y Francisco Gómez y a la familia Lalecorí de Colonia Nechochea por ofrecer generosamente sus conocimientos, por su ayuda en el trabajo de campo y por su hospitalidad desinteresada. A Pastor Arenas por haber motivado nuestro interés en el tema y por la bibliografía suministrada, a Mariangeles Gaviorno por compartir sus datos y a Ula Karlin por la bibliografía cedida. Finalmente al Consejo 
Nacional de Investigaciones Científicas y Técnicas de Argentina por financiar nuestras investigaciones.

\section{Bibliografía}

ALANÍS, R. 1947. Material arqueológico de la civilización diaguita. Museo Arqueológico Regional "Inca Huasi", La Rioja. 125 pp.

ÁlVAREZ, A. 1926. El Meteorito del Chaco. Peuser, Bs. As. 222 pp.

AMBROSETTI, J.B. 1894. Apuntes sobre los indios chunupíes (Chaco austral) y pequeño vocabulario. An. Soc. Cient. Arg. 37: 150-160.

AMBROSETTI, J.B. 1899. Notas de arqueología calchaquí. Instituto Geográfico Argentino 20: 253302. Bs. As.

ARENAS, P. 2003. Etnografía y alimentación entre los Toba-Ñachilamole\#ek y Wichí-Lhuku'tas del Chaco Central (Argentina). Ed. del autor, Bs. As. $562 \mathrm{pp}$.

CAPPARELli, A., M.L. POCHETTINO; D. ANDREONI \& R.D. ITURRIZA. 2006. Differences between written and archaeological record: The case of plant micro remains recovered at a Northwestern Argentinean Pipe. Proceedings of the IVth International Congress of Ethnobotany (ICEB 2005), pp. 397-406.

CARRANZA, A.J. [1884] 1972. Diario de Marcha de la Expedición de 1884 redactado por el doctor Angel Justiniano Carranza. En A. Scunio, La conquista del Chaco, pp. 363-436. Círculo Militar, Bs. As.

COBO, B. [1653] 1964. Historia del Nuevo Mundo. Biblioteca de Autores Españoles, tomos 91 y 92. Ediciones Atlas, Madrid. 207 pp.

COCUCCI, A.A. \& A.T. HUNZIKER. 2005. Solanaceae. Subtribu VIIa. Nicotianinae, parte A. 1. Nicotiana L. Flora Fanerogámica Argentina 256: 1-15.

COMES, O. 1899. Monographie du genre Nicotiana. Typographie Coóperative, Nápoles. 80 pp.

DI LULLO, O. 1929. La medicina popular de Santiago del Estero. El Liberal, Santiago del Estero.171 pp.

DOBRIZHOFFER, M. [1784] 1967. Historia de los abipones. Vol. 1. Universidad Nacional del Nordeste, Resistencia. 569 pp.

FABERMAN, J. 2005. Las Salamancas de Lorenza. Magia, Hechicería y Curanderismo en el Tucumán Colonial. Bs. As., Siglo XXI. 286 pp.

FILIPOV,A. 1996. Estudio etnobotánico de la recolección entre los Pilagá. Tesis Doctoral, Facultad de Ciencias Naturales y Museo de la Universidad Nacional de La Plata. 191 pp.

FURLONG, G. 1938. Entre los mocobíes de Santa Fe. Según las noticias de los misioneros jesuitas Joaquín Camaño; Manuel Canelas; Francisco
Burgués, Román Arto, Antonio Bustillo y Florián Baucke. Amorrortu e Hijos, Bs. As. 233 pp.

FURST, P.T. 1980. Los alucinógenos y la cultura. Fondo de Cultura Económica, México. 335 pp.

GOODSPEED, T.H. 1954. The genus Nicotiana. Origins, relationships and evolution of its species in the light of their distribution, morphology and cytogenetics. Chron. Bot. 16. 536 pp.

JOLÍS, J. ([1789] 1972). Ensayo sobre la historia natural del Gran Chaco. Universidad Nacional del Nordeste, Resistencia. 393 pp.

KNAPP, S.; M.W. CHASE \& J.J. CLARKSON. 2004. Nomenclatural changes and a new sectional classification in Nicotiana (Solanaceae). Taxon 53(1): 73-82.

KVIST, L.P. \& M.R. MORAES. 2006. Plantas psicoactivas. Botánica Económica de los Andes Centrales, pp. 294-312. La Paz, Bolivia.

LOZANO, P. [1754-1755] 1875. Historia de la conquista del Paraguay, Río de Ia Plata y Tucumán. Vol. 5. Imprenta Popular, Bs. As. 377 pp.

MARTÍNEZ CROVETTO, R. 1964. Estudios etnobotánicos I. Nombres de plantas y su utilidad, según los indios tobas del este del Chaco. Bonplandia (Corrientes) 1(4): 279-333.

. 1965. Estudios etnobotánicos II. Nombres de plantas y su utilidad, según los indios vilelas del Chaco. Bonplandia (Corrientes) 2(1): 1-23.

- 1968. Estado actual de las tribus mocovíes del Chaco (República Argentina). Etnobiologica 7: $1-23$.

1978. Una nueva especie de Nicotiana de la flora argentina. Bonplandia (Corrientes) 5(2): 7-10.

—. 1980. Identificación botánica del "coro", antiguo fumatorio utilizado por los indios del Chaco (Rep. Argentina). En Editores Mexicanos Unidos (eds.), La Antropología Americanista en la Actualidad. Homenaje a Raphael Girard. Tomo 2, pp. 455-463. México. $596 \mathrm{pp}$.

MÉTRAUX, A. 1996. Etnografía del Chaco. Biblioteca paraguaya, Vol. 1 de Colección Antropología. El Lector, Paraguay. 271 pp.

MILLÁN, A.R. 1928. Las especies del género Nicotiana de la Flora argentina. Revista Fac. Agron. Veterin. 6(2): 169-216 (+ 6 láms).

MOERMAN, D.E. 1998. Native American Ethnobotany. Timber Press, Portland. 927 pp.

MONTENEGRO, P. [1710] 1945. Materia Médica Misionera. Biblioteca Nacional, Bs. As.

OBLITAS POBLETE, E. 1969. Plantas medicinales en Bolivia. Farmacopea Callawaya. Los amigos del libro, La Paz, Bolivia. 529 pp.

PÉREZ GOLLÁN, J.A. \& I. GORDILLO. $1993 \mathrm{a}$. Alucinógenos y sociedades indígenas del noroeste argentino. Anales de Antropología 30: 299-350. México.

. 1993b. Religión y alucinógenos en el antiguo 
noroeste argentino. Ciencia Hoy 4 (22): 50-63. . 1994. Vilca Uturuncu. Hacia una arqueología del uso de alucinógenos en las sociedades prehispánicas de los Andes del Sur. Cuicuilco 1(1): 99-140.

RODRÍGUEZ, J.E. 1927. Campañas del desierto (expediciones premiadas). Imprenta López, Bs. As.

ROJAS ACOSTA, N. 1915. Historia natural de Corrientes i del Chaco. Ed. Dupuis, Resistencia. 144 pp.

RUIZ MORENO, A. 1948. La medicina en "El Paraguay natural”(1771-1776) del P. José Sánchez Labrador. Universidad Nacional de Tucumán, San Miguel de Tucumán.

SANTAMARÍA, D.J. 2007. Chaco Gualamba. Del monte salvaje al desierto ilustrado. Jacel, San Salvador de Jujuy. 191 pp.

SCARPA, G.F. 2000. Estudio etnobotánico de la subsistencia de los criollos del Chaco Noroccidental argentino. Facultad de Ciencias Exactas y Naturales de la Universidad de Buenos Aires. 351 pp. +12 láms.

SCHERY, R.W. 1952. Plants for man. Prentice-Hall, New York. 564 pp.

SCHULTZ, A.G. 1963. Plantas y frutos comestibles de la región chaqueña. Revista Agron. Noroeste Argent. 4: 57-83.

SOUKUP, J.S. 1970. Vocabulario de los nombres vulgares de la flora peruana. Colegio Salesiano, Lima. 380 pp.

SUÁREZ, M.E. 2011. Etnobotánica wichí del bosque xerófito en el Chaco Semiárido salteño. Tesis Doctoral, Facultad de Ciencias Exactas y Naturales de la Universidad de Buenos Aires.
USDA, ARS, NATIONAL GENETIC RESOURCES PROGRAM. 2011. Germplasm Resources Information Network - (GRIN) [Online Database]. National Germplasm Resources Laboratory, Beltsville, Maryland. URL: http://www.ars-grin. gov/cgi-bin/npgs/html/stdlit.pl?Chron\%20Bot (02 May 2011).

VILLAFUERTE, C. 1961. Voces y costumbres de Catamarca. Tomo I. 399 pp. Tomo II. 417 pp. Academia Argentina de Letras, Bs. As.

VON REIS ALTSCHUL, S. 1975. Drugs and Foods from little-known plants. Harvard University Press, London. 366 pp.

VUOTO, P. 1981. Plantas útiles entre los Tobas Taksek. Entregas del Instituto Tilcara (Jujuy, Argentina) 10: 12-76.

WILBERT, J. 1972. Survivors of El Dorado. Four Indians Cultures of South America. Praeger Publishers, U.S.A.

_. 1987. Tobacco and Shamanism in South America. Yale University Press, U.S.A.

ZARDINI, E.M. 1975. Revisión del género Trichocline (Compositae). Darwiniana 19 (2-4): 618-733.

_ 1977. The identification of an Argentinian narcotic. Bot. Mus. Leafl. 25(3): 105-106.

ZULOAGA, F.O; O. MORRONE \& M. BELGRANO. 2009. Catálogo de las Plantas Vasculares del Cono Sur [en línea]. Instituto de Botánica "Darwinion", San Isidro. Actualizado a Enero de 2009. http:// www2.darwin.edu.ar/Proyectos/FloraArgentina/ FA.asp [Consulta: Octubre de 2011].

Original recibido el 15 de noviembre de 2011; aceptado el 12 de diciembre de 2011. 